\title{
23. Deriving Enterprise Engineering and Integration Frameworks from Supply Chain Management Practices $^{74}$
}

\author{
Angel Ortiz ${ }^{1}$, Víctor Anaya ${ }^{1}$ and Darío Franco ${ }^{1}$ \\ 1 Research Center on Production Management and Engineering, Polytechnic University of \\ Valencia, Spain Email:\{aortiz,vanaya,dfranco\}@cigip.upv.es
}

\begin{abstract}
Enterprise Engineering and Enterprise Integration have been leveraged as key topics in Enterprise Management. Since the $80 \mathrm{~s}$ multiple approaches, methodologies, languages and, frameworks have been proposed. Despite the numerous results currently existing, new trends and solutions are continuously emerging. This paper provides a landscape of the current problems on Enterprise Engineering and Integration, the strategies, solutions and our vision about future irends.
\end{abstract}

\section{INTRODUCTION}

During the past 20 years, firms have faced continues changes in managerial and technological solutions in order to cope with new market objectives and challenges. Companies have moved from individual strategies, where each enterprise did their own work without considering the collaboration with other enterprises, to collaborating strategies, where sharing and exchanging information is necessary to give complete solutions that users demand. On the other hand, enterprises have evolved technologically from an all manual activities situation, to a situation with intensive support by Information Technology (IT).

Analysing multiple solutions, approaches and proposals that historically have tried to improve the management of business entities, we can differentiate two complementary fields of research, Enterprise Engineering and Enterprise Integration. Although complementary, they impact each other in some way, mainly Enterprise Engineering over Enterprise Integration, because to integrate something it is needed to know things that are going to be integrated.

Enterprise Engineering is the art of understanding, defining, specifying, analysing, and implementing business processes for the entire enterprise life-cycle, so that the enterprise can achieve its objectives, be cost-effective, and be more competitive in its market environment (Vernadat, 1995).

Enterprise Integration consists in breaking down organizational barriers to improve synergy within the enterprise so that business goals are achieved in a more productive and efficient way (Vernadat, 2002).

\footnotetext{
${ }^{74}$ This paper was developed in the framework of the INPREX Project (DPI2004-02594). This Project is partially funded by the CICYT of the Spanish Government.
} 
The paper summarises the main topics and future trends that the authors envision in a near future of the area. This vision is stated from the authors' research background and experiences in European research projects, projects with companies and national projects.

- European projects: In ECOSELL (GRD1-2001-40692) and V-CHAIN (DPI2002-11149-E), tile, furniture, automotive and motorcycle, enterprises were analysed and where a lack of integration was detected among and within participating enterprises' processes, taking into account the management of their supply chains. UEML (IST-2001-34229) and INTEROP (IST-1-508011) are concerned with the (mainly inter-)integration of enterprise models and the alignment of these models with the information systems that support them, also including the analysis of enterprise architectures and ontologies and their impact when interoperating.

- Projects with Firms: mainly with SMEs, where solutions to process management and the development of their whole life-cycle were tackled. A main problem has been in these projects that there is a lack of tools that are customizable, accessible at a low cost, and easy to use and update..

- National Projects: where enterprise integration methodologies were developed, problems were identified, classified and possible solutions proposed.

\section{LANDSCAPE}

After analysing the state of the art of Enterprise Engineering and Enterprise Integration the authors have concluded that existing solutions can be classified according to two frameworks (see Figure 1). Each framework is composed of three components at least: Methodologies, Tools and Languages (cf ISO 15704:2000). Methodologies are a set of steps grouped in processes and phases that describe the actions that must be carried out to build up a business, from the conceptual idea to the operation of the enterprise. Methodologies may propose the use of different languages (modelling or implementation languages), according to the application domain, view, and phase within the life-cycle (Petit, M. et al, 2002), although it is not mandatory for a methodology to do so. In the same way, methodologies may refer to tools that could be used to carry out different phases (for example, tools for modelling business processes, or tools to implement the information systems that will execute the processes envisioned in the design phase). On the other hand, there is a need for enterprise engineering tools (cf ISO 15704:2000) that support different phases of the enterprise's construction and support different modelling languages, that permit integrating solutions at different levels of a life-cycle or that permit different integration approaches depending on the languages used.

\subsection{Enterprise Engineering Framework}

Our research center has long been working in this context. In 1999, (Ortiz, 1999a) proposed the IE-GIP framework embracing tools, methodologies and languages. That proposal defined a methodology aiming to cover the entire life-cycle of business entities. The methodology is based on the PERA proposal, and from the architectural point of view, the CIMOSA proposal was adopted whenever possible. On one hand, the life cycle concept of the PERA proposal and several aspects related with human teams, strategic approaches and master planning issues, have been adapted to the business process perspective of IE-GIP (for a description of the 
phases of the life-cycle see (Ortiz, 1999a)). On the other hand, CIMOSA plays a key role in the lower level phases from the Requirements Definition phase to the Implementation Description phase.(see Figure 2).

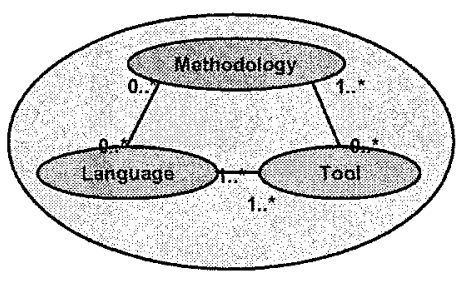

Enterprise Engineering FRAMEWORK

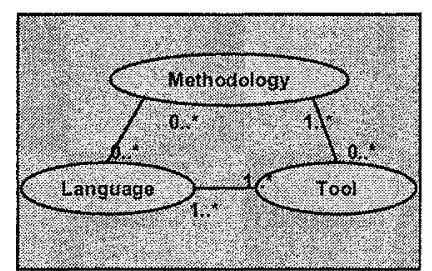

Enterprise Integration FRAMEWORK

Figure 1. Enterprise Engineering and Integration Frameworks

Finally, IE-GIP defined a computer tool called GIPMODEL (Modelling and Management of Integrated Processes, acronym in Spanish) aiming to give a computer-assisted modelling support to the application of the proposal. Furthermore, CILT (CIMOSA Learning Tool) and VR-CILT (Virtual Reality-CIMOSA Learning Tool) tools were developed (Ortiz, 1999b) to cover the conceptual aspects related with the CIMOSA proposal.

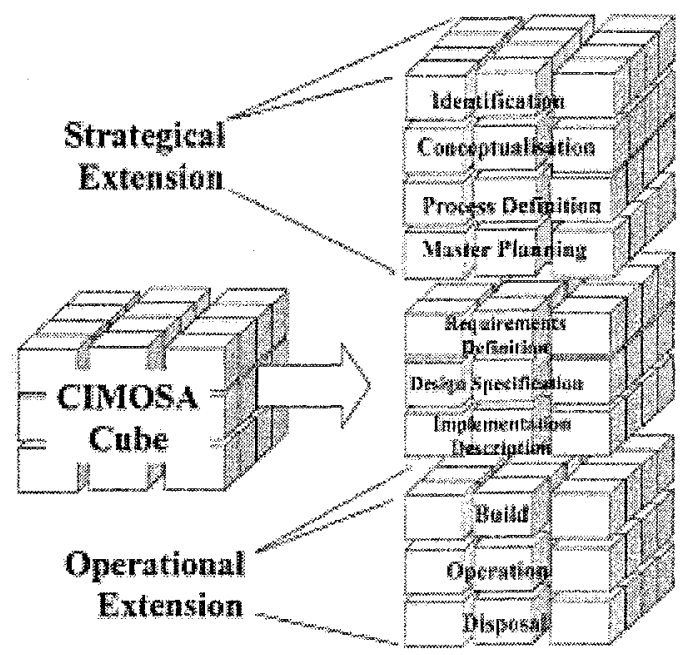

Figure 2. IE-GIP language extension

IE-GIP has been used in a series of projects with SMEs. From this expertise and from the new trends, approaches and technologies we extended IE-GIP's methodology in different ways. Now, it is emphasized the capabilities to automate the generation of software from the enterprise modelling, and to align the strategic, operational and IT levels to keep track, assure enterprise's objectives and make the company more agile against changes. IE-GIP's extension is being refined and tested in a national project called INPREX (Interoperability between Extended Enterprise 
Processes, acronym in English) (see Figure 3 - dark boxes are new or refined phases).

Below, we provide only a further description of those IE-GIP phases that have been extended (darkest boxes in Figure 3):

- Processes Identification: Identification of the processes that will be considered as important to be analysed and improve in order to achieve the business goals defined at the conceptualization phase (for instance, customer orders management process).

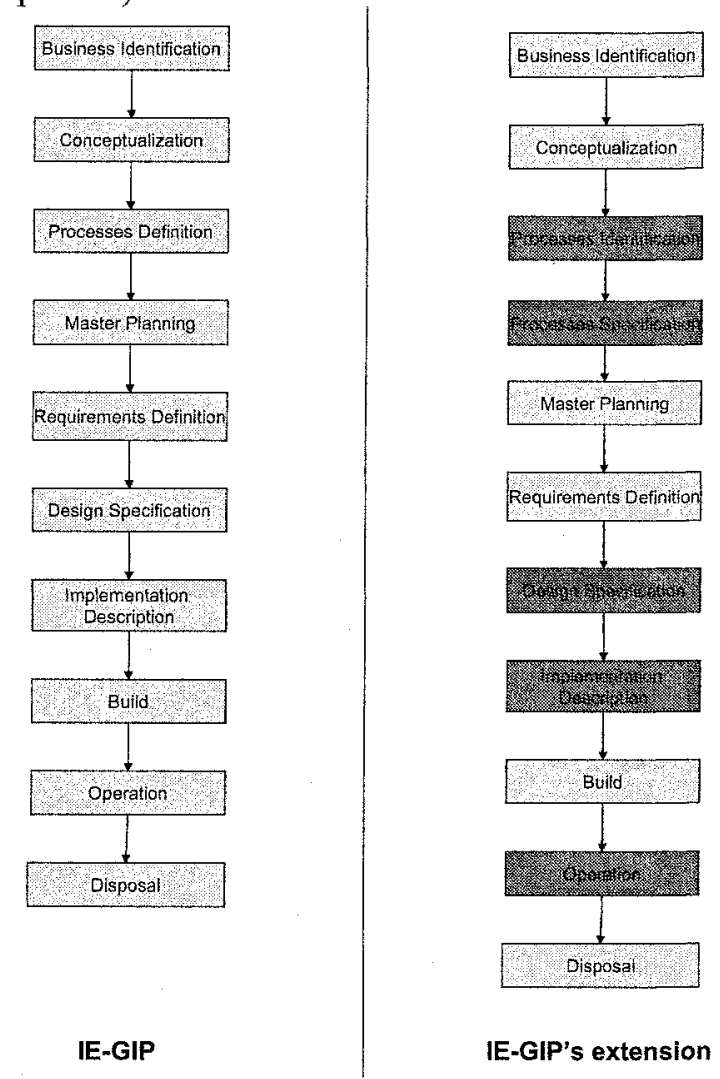

Figure 3. IE-GIP's life-cycle extension

In order to standardise the definition of processes some initiatives have arisen as RosettaNet (www.rosettanet.org) or SCOR (www.supply-chain.org). These proposals also cover standard definition of business processes and specific activities that will be identified in the next phase (Process Specification Phase). The new technological proposals give a more appropriate support to this phase, as for example, the repositories and the enrichment of information with semantics. These repositories contain a formal description of the processes, with their associated semantics, and can be instantiated and parameterised. Examples of these repositories are the ebXML libraries (www.ebxml.org/specs). From an ontological point of view, processes can be described using formal languages such as Description Logic, Frame Logic, DAML or OWL; or semi-formal languages such as UML itself. 
- Processes Specification: processes identified in the previous phases are analysed more deeply. Processes and activities are defined and some of the entity objects are identified. The diagrams are refined until it is enough knowledge in order to analyse the viability of the project at the Master Planning phase.

Enterprise Modelling is a way to express this processes specification. We encourage the use of BPMN (business process modelling notation) as the language to specify processes at an abstract level, although some principles defined in other existing standards (or standard proposals) must be also considered. The choice of BPMN is due to the capabilities to be mapped on BPML and after that, to be supported by some systems in order to run and simulate models.

Some of the previously stated standards are ISO TC184 SC5, WG1 (Business representation), ISO 14258 (concepts and rules for enterprise models) and ISO 15704 (methodologies requirements and enterprise reference architectures). Other standards are CEN TC310 WG1 for high level enterprise modelling and architectures, ENV 12204 for enterprise modelling constructs.

- Processes Design: The enterprise models are enriched and customized for facilitate their execution over platforms.. Processes are classified as executable directly on an IT platform (executable processes) or carried out by humans (manual processes).

Examples of tools able to execute processes in some sense are workflow management systems, systems able to execute in a distributed way business processes (e.g., Vitria $($ ) or more recent business process execution systems such as $\mathrm{n}^{3}$ from Intalio $(\mathbb{B}$. Business Process Management is living a great momentum, with the support of strong groups putting effort on it. For example, BPMI (Business Processes Management Initiative), WfMC (Workflow Management Coalition) and the OMG (Object Management Group.

- Processes Implementation/Implantation: The implementation of IT platform executable processes has been optimised in the IE-GIP extension.

We have taken profit of proposals such as MDA (model driven architecture) to achieve a tighter alignment and to generate (semi)automatically IT systems embedding the logic of business processes (see Figure 4). Further, in (Franco, D., 2003) we define derivation rules that allowing the automatic generation of OWL-S descriptions (semantic descriptions for web services) from enterprise models.

The use of MDA permits us to align Information System (IS) solutions with software requirements (Harmon, 2004), ensuring that software requirements are compliant with enterprise requirements.

The Model Driven Architecture (MDA, www.omg.org/mda) is a proposal of the Object Management Group (OMG) for the generation of software from models. The main idea of MDA is to deduce a model from other model until it is transformed into the code of the application, assuring the compliance between models at different abstraction levels.

MDA distinguishes among three kinds of models (Object Management Group, 2003): the computation-independent model (CIM), the platform independent model (PIM) and platform-specific model (PSM). CIM, also called a domain model, shows the environment in which the system will operate. PIM depicts the information system without considering specific platform/technology. PSM represents the model 
of the IS considering specific platform details. Finally, at the lowest level considers the code of the application in a specific platform.

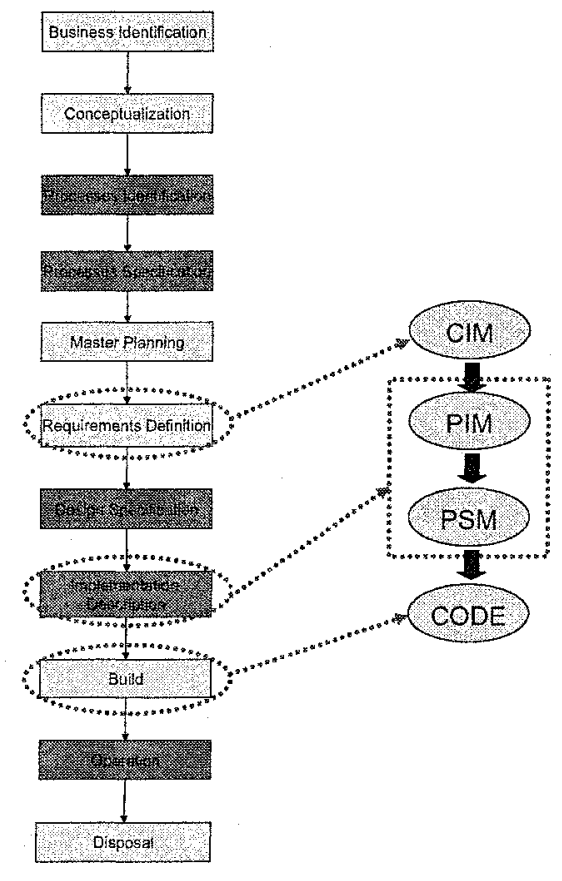

IE-GIP's extension

Figure 4. Phase of Implementation driven by the MDA

- Operation: The IT systems or formal procedures defined in the previous phase are executed. Thus, processes are transformed from a static state to a dynamic state and the execution of theses processes can be managed.

After running processes (automatically or manually), data can be gathered, mainly considering the key performance indicators associated with each process and that where defined in the processes definition phase. With this information, a deep analysis can be done (Business Performance Management) in order to improve processes cost or their execution time, etc; predictions can be made by means of data mining techniques. Thus, an analysis is necessary to check the achievement of current enterprise goals and strategies against the enterprise model/s and to propose new versions.

\subsection{Enterprise Integration Framework}

In order to cope with the global solutions demanded by customers, companies need to collaborate. Collaborative Networks Organisations (CNO) require an extreme exchange of flows (information \& knowledge, material \& services, and money (Ortiz A. Et al, 2003)), a strong support of information technologies and a big motivation of managerial staff in order to achieve integration solutions that provide the visibility and exchange of transactions necessary to do agile network of enterprises. 
Interoperability is the action by means of which two or more active business items (applications, companies, departments within a company, etc) exchange events or flows of information (that is, control, data and decisional information flows, etc) to collaborate.

Enterprises can exchange entity objects at different levels (see Figure 5.). However, we have focused our attention to the exchange at business- and enterprise models level and the integration and collaboration of Enterprise Application.

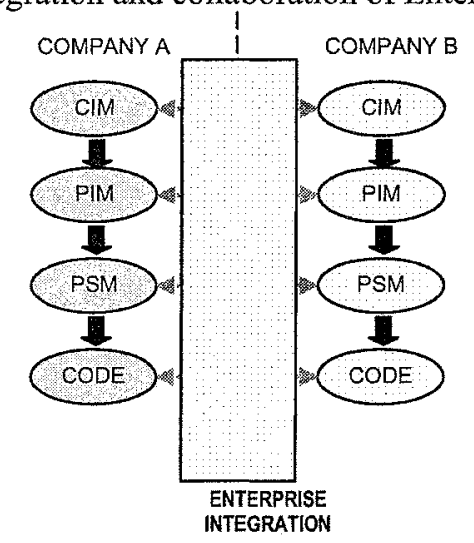

Figure 5. Multilevel Enterprise Integration

\subsection{UEML}

As we have previously mentioned, Enterprise Modelling is the art of externalizing the knowledge of an enterprise to be shareable. Thus, when companies collaborate on a network of enterprises (for instance, a supply chain), they need to exchange enterprise models with other firms. These models are represented in graphical or textual languages, and usually are represented in heterogeneous languages. This fact requires techniques combination and transformation of models across different languages and tools to achieve the required interoperability and integration. UEML (Berio et al, 2004) (Unified Enterprise Modelling Language) is an enterprise modelling language aiming to exchange enterprise models represented using different modelling languages. UEML v1.0 was developed at UEML project ${ }^{75}$ funded by IST Programme of the European Commission $5^{\text {th }}$ Framework.

UEML has been defined as an enterprise modelling language which constructs synthesize concepts appearing commonly in different enterprise modelling languages. In this way, it was found out that many of the building elements that enterprise modelling languages provide, although represented with different terms (syntax), they represent the same or a similar concept. Therefore, UEML appears as an intermediate language use to translate a models between different languages reducing the number of interfaces needed to exchange models in a network of enterprises compared with a peer-to-peer approach (see Figure 6).

Furthermore of the exchange capabilities offered by UEML, It also supports consistency of various model views, insofar as models representing different views of an enterprise (decisional, organizational, functional etc) using different languages

${ }^{75}$ UEML IST-2001-34229 
can be put all together, and keeping links between these views by means of the intermediate relationship offered by UEML as a common connector (see Figure 6).

A list of current and real business problems in which a UEML can play a central role is (Jochem, 2003):

- Lack of Integration of information systems encoding fragmented non sharable enterprise knowledge.

- Shortage of coordination of business processes.

- Multiple views of business operations.

- Poor interoperability of process modelling and management tools.

- Insufficient coverage by most languages of required modelling views.

- Diverse visual representations.

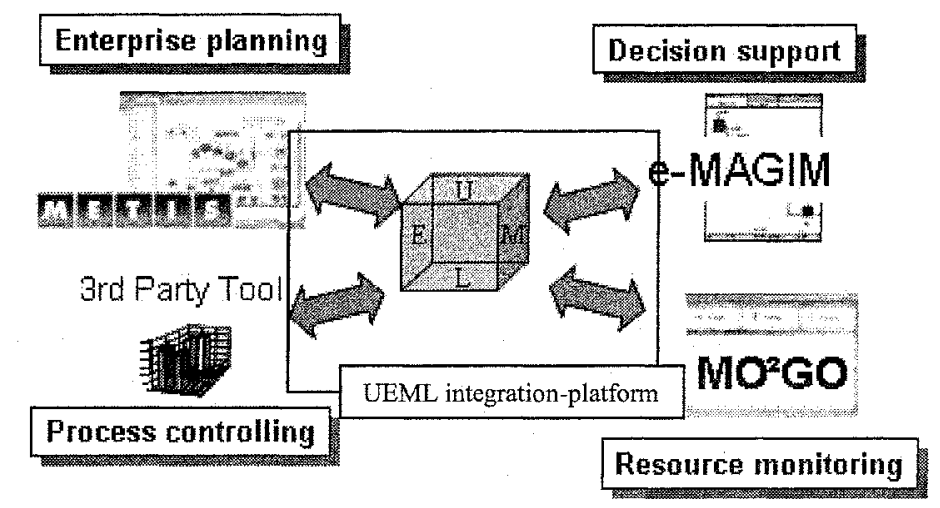

Figure 6. Translations of EMs by using a UEML (Berio, 2004)

\subsection{Enterprise Application Integration}

In a more technological level, there are multiple solutions to achieve a tool-to-tool integration (EAI, B2Bi or eHubs), however these solutions are very specific of the tools that interoperate and they are not very reusable. XML has become a standard to structure messages that enterprise applications exchange in order to communicate with one another.

Now, with the Service Oriented Approach, enterprise integration will be more affordable as far as a better encapsulation is available, and messaging a distribution of applications is well defined.

ATHENA is a European project trying to provide solutions at this level (Chen, 2003).

\subsection{The General Picture}

Figure 7 shows the research paths followed by the authors of this article. Only the main items are shown (those where most effort has been spent), with some smaller efforts omitted from the figure. 


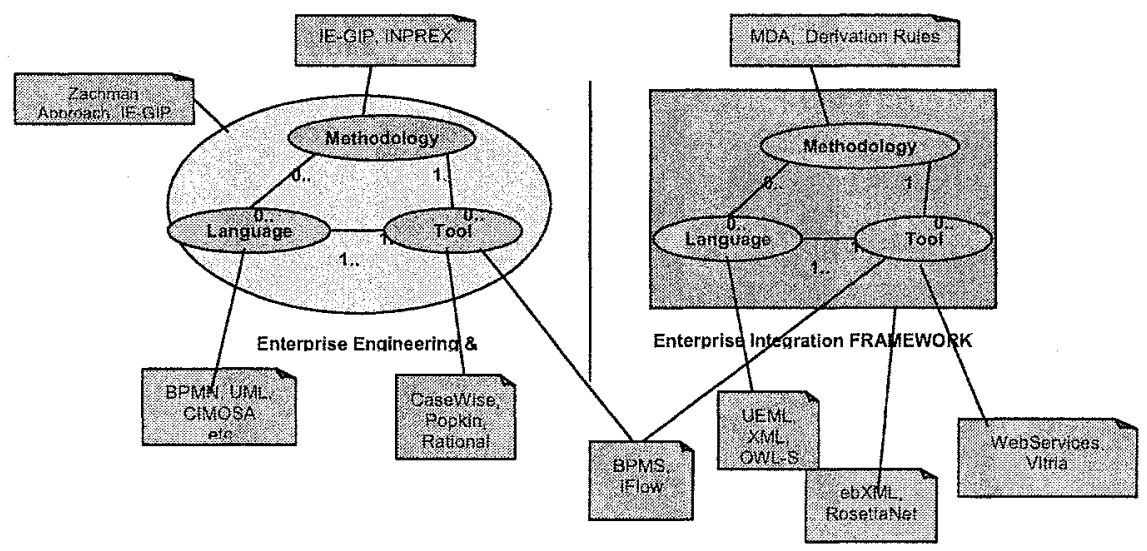

Figure 7. Research Summary

\section{CONCLUSIONS}

Despite many results generated in the enterprise integration / enterprise engineering field, problems still remain in the area. Some of these are listed below:

- Improper or poor use of methodologies and tools, when practicing enterprise engineering, frequently the models generated are of poor quality and become obsolete very fast.

- Low visibility of end-to-end processes and associated information within network of enterprises.

- Lack of alignment among strategic, operational and technological aspects of an enterprise, so enterprise can not manage properly changes necessaries to cover customer or market evolving requirements/needs.

The authors envisage that solutions to these problems (most of them commented at the previous ICEIMT (Kosanke et al, 2003)):

- Developing and disseminating easy-to-use and user-friendly enterprise modelling languages (mainly addressing problems of SMEs) as a means to exchange information between enterprises, but also within the enterprise.

- Following clear and intuitive methodologies that assure the quality of business documents and enterprise models. In this way, our extended methodology can be customized to specific needs and follows proposals and languages that permit the semi-automatic implementation of applications from enterprise models. Further, a better aligned of strategic, operational and IT levels is achieve. Thus, we can evaluate the IT solutions developed are contributing to the achievement of the business entity goals.

- Enforcing industry standards whenever possible.

\section{REFERENCES}

Berio,G, Anaya,V, Ortiz,A (2004) Supporting Enterprise Integration through a Unified Enterprise Modeling Language. In INTEROP-EMOI Proceeding. A Caise2004 Workshop. Vol 3. pp. 165-176. ISBN:9984-9767-3-4. Riga, Latvia. 
Chen,D, Doumeingts, G (2003) European initiatives to develop interoperability of enterprise applications - basic concepts, framework and roadmap. Annual Reviews in Control 27, pp 153-162. Elsevier.

ENV 12204 : Advanced Manufacturing Technology - Systems Architecture Constructs for Enterprise Modelling, CEN TC 310/WG1, 1996

Franco,D, Anaya,V, Ortiz,A (2003) Automatic Derivation of DAML-S Service Specifications from UML Business Models. Lecture Notes in Computer Science. Springer-Verlang Berlin Heidelberg. ISBN: 0302-9743.

Harmon,P (2004) The OMG's Model Driven Architecture and BPM. Business Process Trends Newsletter. Vol 2, No 5 May. www.bptrends.com

ISO/TC 184/SC 5. Industrial automation systems - concepts and rules for enterprise models. Technical Report ISO 14258, Web version WG1 N4, ISO, 1999. http://www.mel.nist.gov/sc5wg1/std-dft.htm.

ISO 14258:1998, Industrial automation systems -- Concepts and rules for enterprise models, TC 184/SC 5, 1998

ISO 15704:2000, Industrial automation systems -- Requirements for enterprisereference architectures and methodologies, TC 184/SC 5, 2000.

Jochem,R (2003) Common Representation through UEML-Requirements and Approach. International Conference on Enterprise Integration and Modelling Technology. Enterprise Inter- and Intra-Organizational Integration. Kluwer, Valencia, Spain.

Kosanke, K., Jochem R., Nell, J., Ortiz, A. (2003) Enterprise Inter- and IntraOrganizational Integration. Building International Consensus. Kluwer Academic Publishers, ISBN: 1-4020-7277-5.

Ortiz,A, Franco,R.D, Alba,M (2003) V-CHAIN: Migrating from Extended to Virtual Enterprise within an Automotive Supply Chain. PROVE'03 Proceedings. Processes and Foundations for Virtual Organizations.

Ortiz,A, Lario,F, Ros,L (1999a) Enterprise Integration-Business Processes Integrated Management: a proposal for a methodology to develop Enterprise Integration Programs. Computer in Industry, 40, pp.155-171, Elsevier.

Ortiz, A., Lario, F., Ros, L. and Hawa, M. (1999b) Building a Production Planning Process using an Approach based on CIMOSA and Workflow Management Systems Computers in Industry. Vol. 40. pp. 207-219. Elsevier

Object Management Group, "MDA guide version 1.0", OMG, 2003.

Petit, M, et al (2002) D1.1: State of the Art in Enterprise Modelling, UEML-IST2001-34229, www.ueml.org.

Vernadat, F.B (1996) Enterprise Modelling and Integration: principles and applications. Chapman \& Hall, London.

Vernadat,F.B (2002) Enterprise Modelling and Integration (EMI): Current Status and Research Perspectives. 